\title{
Evaluation Model of College Students' Sports Learning Engagement Factors Based on Big Data Analysis*
}

\author{
Qinghua Zhang ${ }^{1}$ \\ China University of Mining and Technology
}

\begin{abstract}
Through big data analysis for the questionnaire of college students' sports learning engagement, the analysis results show that the overall situation of students' learning engagement is general, and there are differences in gender and grade. Regression analysis shows that social support and self-factors play a predictive role in the learning engagement of sports students. A learning engagement evaluation model which consists of five factors: active cooperative learning level, deep learning method, theoretical course learning engagement, professional training engagement and expansive learning engagement is proposed. Through the analysis of the questionnaires, it is concluded that the model can be used in the management and research of the evaluation of the learning engagement of sports students.
\end{abstract}

\section{Keywords}

Learning Engagement $\bullet$ Sports Students $\bullet$ Evaluation Model $\bullet$ Big Data Analysis $\bullet$ Self-Factors

\footnotetext{
* The research projects of the "Double Top-Class" universities Construction Program of China University of Mining and Technology (2018WHCC10).

${ }^{1}$ Correspondence to: Qinghua Zhang (MSc), School of Physical Education, China University of Mining and Technology, Xuzhou 221116, China. Email: zqhoumt@163.com
}

Citation: Zhang, Q. H., Evaluation model of college students' sports learning engagement factors based on big data analysis. Educational Sciences: Theory \& Practice, 18(5), 2097-2107. http://dx.doi.org/10.12738/estp.2018.5.109 
Zhang / Evaluation model of college students' sports learning engagement factors based on big data analysis

Learning engagement is a positive and enriching mental state related to learning, which includes three dimensions: vitality, dedication and focus (Schaufeli, Salanova, González-romá, \& Bakker, 2002). Some scholars define learning engagement as follows: learning engagement is a lasting, positive and complete emotional and cognitive psychological state related to learning, scientific research and employment (Mazer, 2013).

The quality of education is the lifeline of the development of colleges and universities, and students' learning results directly feedback the quality of higher education. Kuhn once said: the core factor of the education quality is the engagement level of students (Kuh, 2001). However, the learning situation of students in colleges is not optimistic in recent years. Especially, sports students generally have some problems, such as lack of interest in professional learning, unreasonable allocation of learning time and so on. As the reserve force of sports talents, the low engagement of sports students seriously affects the students' academic performance and the development of national sports undertakings. Therefore, the education of sports students should be paid great attention to.

By investigating the learning engagement of students majoring in physical education, the factors affecting their learning engagement were found out. We can fundamentally find out the factors that motivate students' learning enthusiasm, and the basis for improving the physical education teaching and students' learning engagement in colleges is provided in this paper.

\section{Related works}

In recent years, many researchers have devoted themselves to the study of students' learning engagement. Weidenfeld \& Fernandez (2016), pointed out that the success and development of students are the direct evidence of the quality of education, so the evaluation index of learning input gradually pays attention to students' academic achievements and professional abilities. Sibold (2016) proposed a learning theory based on their long-distance education practice. The basic idea is that the effectiveness of learning is that learners must actively engage in learning. King \& Witney, (1998) considered that benefits of students in cognition, skills and attitudes are the core criteria to measure the quality of higher education. Newmann (1992) believe that learning engagement is not only a simple way to listen to classes and finish homework, but also a feeling of students' success in learning and pride in the production of research results.

Tian \& Zhang, (2012) pointed out that the theoretical basis of Chinese college students "learning engagement mainly includes six classical theories, student development theory, constructivism theory, total quality management theory and so on. Beyraamee, Haashemee, Abdollaahee \& Alaaee, (2011) think that students 'learning engagement is actually a state of students' active knowledge seeking, which plays a very important role in promoting students' learning process. The state includes vitality, dedication and concentration, vibrancy is the good psychological state that students maintain in order to seek knowledge, enrich themselves, and strong desire for knowledge; dedication refers to the efforts and challenges that students make in order to achieve a certain learning goal and accomplish a certain learning task in learning, dedication is the goal orientation in learning process. Liao et al. believe that learning engagement is one of the three elements of behavior, emotion and cognition. On the basis of this single factor input, many scholars have proposed that learning engagement 
is a variable with multiple meanings (Liao, 2011). Hu et al. conducted a comprehensive study on students' learning engagement by means of student questionnaire, teacher evaluation, case analysis and classroom observation. The results showed that the results of the questionnaire survey on students' learning engagement were consistent with those of teachers' evaluation on students' learning engagement (Hu, Zhou, Yang \& Ran, 2009). Gregg (2012) researched on national survey of student engagement (NSSE) in the process of research on students' learning engagement, they believed that NSSE is a relatively authoritative and widely accepted scale for measuring the learning engagement of college students.

Tian and Deng, (2016) sent out questionnaires to some students of five universities in Gansu province, they tried to get the status quo of learning engagement of students, and gave relevant suggestions. Pitsi, Digelidis, \& Papaioannou, (2015) draw lessons from NSSE's theory and practice, they take students' participation experience as the theoretical basis, and draw a new way of higher education evaluation. They pay attention to students' investigation and strengthen students 'participation in teaching management. Zhang, Bian, \& Xu, (2008) conducted a comparative study of students 'learning engagement in three sports universities by means of questionnaires. The results show that among the five dimensions of students' learning engagement in sports universities, there are advantages and disadvantages in each university.

\section{Questionnaire of college students' sports learning engagement based on big data analysis}

\section{Design of questionnaire}

In this study, a total of 5609 questionnaires were collected from 27 college students majoring in physical education, there are 5467 questionnaires valid. Among them, female accounted for $44 \%$ and male accounted for $56 \%$.

The questionnaire is divided into 3 dimensions: vitality, dedication and concentration. It was initially made up of 13 items, which is shown as Table 1.

Table 1

\begin{tabular}{ll} 
Testing Indicators and Related Instruments \\
\hline No. & \multicolumn{1}{c}{ Item } \\
\hline 1 & When I get up in the morning, I am willing to learn. \\
2 & I feel energetic when I study. \\
3 & Even if the study is not smooth, I will not be discouraged and be persistent. \\
4 & In learning, even if I am mentally tired, I can recover quickly. \\
5 & When I studied, I was strong and energetic. \\
6 & I find learning challenging. \\
7 & Learning inspires me. \\
8 & I am passionate about learning. \\
9 & I am proud of my study. \\
10 & I find learning goals clear and meaningful. \\
11 & When I study, I forget everything around me. \\
12 & When I studied, I felt that time passed quickly. \\
13 & I feel very happy when I devote myself to studying. \\
\hline
\end{tabular}




\section{Big data analysis of questionnaire}

By using the raw data obtained, we get the critical value $\mathrm{CR}$ of the items in the scale. Items that have not reached a significant level are identified and deleted. The elimination of certain items can improve the reliability and validity of the questionnaire, and the final purpose is to show the best reliability and validity.

Firstly, the total score of each participant in learning engagement scale are calculated. The 1200 participants were divided into high and low groups averagely, and the difference was analyzed by t-test. Independent sample $\mathrm{t}$-test was used to test the difference of the average number of each item. If the CR value reached a significant level of 0.05 , it indicated that the item could identify the reaction degree of different participants, and the item could be retained. On the contrary, deletion or alteration of the item should be considered. The first item P > 0.05 , it did not reach the significant level of 0.05 , so the first item was deleted. Except for item 1, the t-test of the average difference of the high and low groups of the other 12 items all reached significant level of 0.05 . Comparison of high and low group is shown as Table 2.

Table 2

Comparison of High and Low Group

\begin{tabular}{lccccc}
\hline \multicolumn{2}{l}{ Levene-test of variance equation } & \multicolumn{2}{c}{ t-test of mean value equation } \\
\hline Item & $\mathrm{F}$ & $\mathrm{Sig}$ & $\mathrm{t}$ & Mean difference & Standard error value \\
\hline T1 & 1.257 & 0.261 & 15.547 & 1.598 & 0.102 \\
T2 & 18.697 & 0.000 & 16.683 & 1.562 & 0.092 \\
T3 & 15.321 & 0.000 & 15.007 & 1.503 & 0.100 \\
T4 & 19.589 & 0.000 & 19.926 & 1.551 & 0.091 \\
T5 & 22.625 & 0.000 & 22.461 & 1.766 & 0.078 \\
T6 & 40.312 & 0.000 & 19.642 & 1.706 & 0.086 \\
T7 & 40.423 & 0.000 & 20.622 & 1.697 & 0.082 \\
T8 & 19.622 & 0.000 & 25.532 & 1.886 & 0.072 \\
T9 & 24.978 & 0.000 & 19.256 & 1.689 & 0.089 \\
T10 & 15.106 & 0.000 & 20.652 & 1.732 & 0.085 \\
T11 & 7.527 & 0.003 & 18.832 & 1.682 & 0.088 \\
T12 & 38.721 & 0.000 & 17.523 & 1.646 & 0.095 \\
T13 & 29.878 & 0.000 & 17.651 & 1.648 & 0.094 \\
\hline
\end{tabular}

Before factor analysis, we first test the adaptability of data. The KMO coefficient is 0.952 and the Bartlett spherical test is 0.000 , which indicates that factor analysis can be carried out.

Table 3

Exploratory Factor Analysis of Learning Engagement Questionnaire

\begin{tabular}{|c|c|c|c|}
\hline Item & Vitality & Dedication & Concentration \\
\hline T2(vitality1) & 0.866 & & \\
\hline T3(vitality2) & 0.752 & & \\
\hline T4(vitality3) & 0.638 & & \\
\hline T6(dedication1) & & 0.715 & \\
\hline T7(dedication2) & & 0.768 & \\
\hline T8(dedication3) & & 0.669 & \\
\hline T9(dedication4) & & 0.675 & \\
\hline T10(dedication5) & & 0.672 & \\
\hline T11(concentration 1$)$ & & & 0.819 \\
\hline $\mathrm{T} 12$ (concentration2) & & & 0.716 \\
\hline T13(concentration3) & & & 0.606 \\
\hline
\end{tabular}

Principal Component Analysis (PCA) is applied to the questionnaire of learning engagement. The load matrix is obtained by using the maximum variance orthogonal rotation method and eliminating the small 
Zhang / Evaluation model of college students' sports learning engagement factors based on big data analysis

coefficient less than 0.40 . After deleting the first item, the other 12 factors are analyzed by exploratory factor analysis. Items 2, 3, 4 and 5 belong to the dimension of vitality. However, since item 5 exists in two loads at the same time, and item 2, 3 and 4 are in the same load, the item 5 is deleted. After deleting the 1,5 items, the results of exploratory factor analysis are shown again in Table 3.

The vitality factors include $\mathrm{T} 2, \mathrm{~T} 3$ and $\mathrm{T} 4$, the dedication factor include $\mathrm{T} 6, \mathrm{~T} 7, \mathrm{~T} 8, \mathrm{~T} 9$ and $\mathrm{T} 10$, the concentration factor include T11, T12 and T13. The percentage of accumulative explanation is $74.38 \%$, which indicates that these three factors reflect the components of learning engagement better in structure. The eigenvalue of factor 1 which is named as vitality is 3.376 , and the contribution rate is $30.82 \%$. The eigenvalue of factor 2 which is named as dedication is 2.398 , and the contribution rate is $22.33 \%$. The eigenvalue of factor 3 which is named as concentration is 2.286 , and the contribution rate is $21.23 \%$.

Because exploratory factor analysis does not consider whether it is suitable in theory and whether the structure is reliable and effective, it can be tested by confirmatory factor analysis. Confirmative factor analysis (CFA) is a relationship model between a group of variables based on the relevant theories and existing knowledge, inferences and assumptions. It tests whether the relationship between a factor and its corresponding measure items conforms to the theoretical relationship designed by the researchers. Its main purpose is to explore the integration ability of the factor model defined beforehand and the actual data in an attempt to test whether the number of factors and the factor load of the observed variables are consistent with the expectations of the established theory. During the process of confirmative factor analysis, fit indexes, such as $\chi^{2} / d f$, NFI, IFI, CFI, AGFI, RMSEA, were measured and examined.

By using hypothesis to carry out confirmatory factor analysis, we examined the rationality of the structural dimension of sports students' learning engagement. The revised model by verifying the path map of the standardized solution is obtained by confirmatory factor analysis. The learning engagement model standardized parameter diagram is shown in Figure 1.

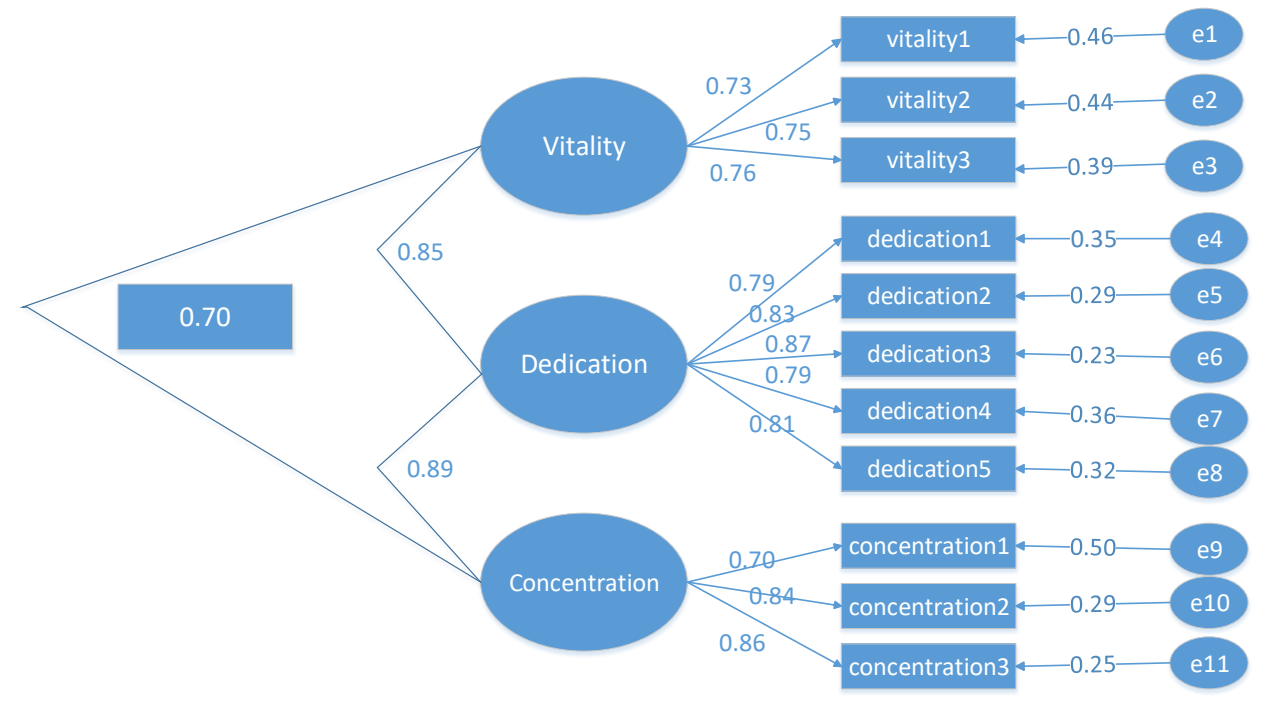

Figure 1. The learning engagement model standardized parameter diagram 
Zhang / Evaluation model of college students' sports learning engagement factors based on big data analysis

Questionnaire confirmatory factor analysis main fit index is show as Table 4.

Table 4

Questionnaire Confirmatory Factor Analysis Main Fit Index

\begin{tabular}{cccccccccc}
\hline$\chi^{2}$ & $d f$ & $\chi^{2} / d f$ & GFI & AGFI & RMSEA & CFI & IFI & NFI & RMR \\
\hline 177.83 & 41 & 4.33 & 0.928 & 0.891 & 0.086 & 0.956 & 0.957 & 0.947 & 0.038 \\
\hline
\end{tabular}

From Table 3 we can see that the value of $\chi^{2} / d f$ is less than 5 , the value of RMSEA is 0.087 , it is an ideal index. From the fit degree, NFI, IFI, CFI, AGFI are all greater than 0.9, RMR is less than 0.05. It shows that the three factors have better fit degree.

\section{Results and analysis}

The overall situation of learning engagement for PE Majors is show as Table 5.

Table 5

The Overall Situation of Learning Engagement for PE Majors

\begin{tabular}{lcccc}
\hline & Learning engagement & Vitality & Dedication & Concentration \\
\hline Mean value & 3.39 & 3.18 & 3.46 & 3.49 \\
Standard deviation & 0.75 & 0.78 & 0.82 & 0.86 \\
Cumulative percentage (\%) & 69.9 & 55.6 & 66.2 & 66.8 \\
\hline
\end{tabular}

From Table 5 we can see that the overall situation of sports students' learning engagement is not very good. The questionnaire adopted the Likert five-point scoring method, its theoretical mean is 3 . Although the average score of learning engagement is higher than 3 , the total cumulative percentage is only $70 \%$. It shows that the students in Physical Education in colleges have only reached $70 \%$ of their engagement in learning. Generally speaking, the students in higher education should be significantly higher than the students in basic education. The accumulative percentage of the three factors of vitality, dedication and concentration is not more than $70 \%$. There is still much room for improvement.

Table 6

Different Gender of Students Learning Engagement Comparison

\begin{tabular}{lcccc}
\hline & Male $\mathrm{M} \pm \mathrm{SD}$ & Female $\mathrm{M} \pm \mathrm{SD}$ & $\mathrm{t}$ & $\mathrm{P}$ \\
\hline Learning engagement & $3.31 \pm 0.82$ & $3.46 \pm 0.68$ & $-2.278^{*}$ & 0.003 \\
Vitality & $3.09 \pm 0.82$ & $3.26 \pm 0.4$ & -2.541 & 0.006 \\
Dedication & $3.36 \pm 0.89$ & $3.51 \pm 0.75$ & $-2.076^{*}$ & 0.004 \\
Concentration & $3.45 \pm 0.93$ & $3.56 \pm 0.79$ & $-1.851^{*}$ & 0.027 \\
\hline
\end{tabular}

Note. $* \mathrm{P}<0.05, * * \mathrm{P}<0.01$

Gender is taken as independent variable and the mean scores of each factor of learning engagement and learning engagement as dependent variable, t-test was carried out. The results are shown as Table 6.

There was no significant difference in the scores of the active factors of learning engagement between male and female. It indicates that there was no significant difference in the active factors between male and female. Scores of male are significantly lower than female in learning engagement, dedication and concentration. It means that male is less likely to learning engagement, dedication and concentration than female.

Grade factors were taken as independent variables, learning engagement and scores of each factor as dependent variables, variance analysis and post-test were carried out. The results are shown in Table 7 and Table 8 . 
Table 7

Different Grades of Students Learning Engagement Comparison

\begin{tabular}{lcccc}
\hline & Learning engagement & Vitality & Dedication & Concentration \\
\hline Freshman & $3.22 \pm 0.82$ & $3.02 \pm 0.83$ & $3.18 \pm 0.87$ & $3.39 \pm 0.92$ \\
Sophomore & $3.26 \pm 0.82$ & $3.13 \pm 0.84$ & $3.32 \pm 0.87$ & $3.36 \pm 0.91$ \\
Junior & $3.32 \pm 0.68$ & $3.26 \pm 0.83$ & $3.33 \pm 0.68$ & $3.34 \pm 0.82$ \\
Senior & $3.41 \pm 0.69$ & $3.28 \pm 0.78$ & $3.45 \pm 0.78$ & $3.43 \pm 0.79$ \\
First year graduate students & $3.58 \pm 0.76$ & $3.39 \pm 0.85$ & $3.63 \pm 0.87$ & $3.76 \pm 0.68$ \\
Second year graduate students & $3.59 \pm 0.78$ & $3.41 \pm 0.61$ & $3.65 \pm 0.66$ & $3.67 \pm 0.67$ \\
Third year graduate students & $3.87 \pm 0.77$ & $3.66 \pm 0.82$ & $3.98 \pm 0.86$ & $3.86 \pm 0.68$ \\
F & $3.813^{* *}$ & $2.478^{*}$ & $3.886^{* *}$ & $3.431^{* *}$ \\
$\mathrm{P}$ & 0.001 & 0.021 & 0.001 & 0.003 \\
\hline
\end{tabular}

Note. $* \mathrm{P}<0.05, * * \mathrm{P}<0.01$

Factor analysis of variance found that the average score of undergraduates and postgraduates was between 3 and 4 points, which indicated that the students' learning engagement, dedication and concentration were in the middle, and did not reach a high level of learning engagement. There are significant differences in learning engagement and scores of various factors among different grades of students majoring in physical education. From freshman to postgraduate, the students 'learning engagement, vitality and dedication are in an increasing state. It shows that with the increase of age and experience, the students' learning engagement, vitality and dedication are also in an increasing state.

Multiple comparisons of learning engagement among students of different grades are shown in Table 8 .

Table 8

Multiple Comparisons of Learning Engagement Among Students of Different Grades

\begin{tabular}{|c|c|c|c|c|}
\hline Dependent variable & (I) & $(\mathrm{J})$ & $\begin{array}{c}\text { Mean difference } \\
(\mathrm{I}-\mathrm{J})\end{array}$ & Significance \\
\hline \multirow{6}{*}{ Learning engagement } & \multirow{6}{*}{1} & 2 & -0.06287 & 0.618 \\
\hline & & 3 & -0.09842 & 0.420 \\
\hline & & 4 & -0.20212 & 0.081 \\
\hline & & 5 & $-0.3782^{*}$ & 0.001 \\
\hline & & 6 & -0.3781 & 0.052 \\
\hline & & 7 & -0.67213 & 0.001 \\
\hline \multirow{6}{*}{ Vitality } & \multirow{6}{*}{1} & 2 & -0.14886 & 0.292 \\
\hline & & 3 & -0.23591 & 0.076 \\
\hline & & 4 & $-0.26134 *$ & 0.035 \\
\hline & & 5 & $-0.37323^{*}$ & 0.003 \\
\hline & & 6 & -0.40215 & 0.063 \\
\hline & & 7 & $-0.62356^{*}$ & 0.002 \\
\hline \multirow{6}{*}{ Dedication } & \multirow{6}{*}{1} & 2 & -0.11621 & 0.405 \\
\hline & & 3 & -0.11824 & 0.372 \\
\hline & & 4 & -0.25036 & 0.047 \\
\hline & & 5 & $-0.49034 *$ & 0.001 \\
\hline & & 6 & -0.41367 & 0.049 \\
\hline & & 7 & $-0.77421 *$ & 0.001 \\
\hline \multirow{6}{*}{ Concentration } & \multirow{6}{*}{1} & 2 & 0.10928 & 0.449 \\
\hline & & 3 & 0.07821 & 0.576 \\
\hline & & 4 & -0.05782 & 0.679 \\
\hline & & 5 & $-0.33756^{*}$ & 0.010 \\
\hline & & 6 & -0.29298 & 0.192 \\
\hline & & 7 & -0.45576 & 0.033 \\
\hline
\end{tabular}


Zhang / Evaluation model of college students' sports learning engagement factors based on big data analysis

After multiple comparisons, it is found that the average difference between freshmen and graduate students is significant, and the average difference is negative, which indicates that the average score of freshmen is significantly lower than that graduate students of learning engagement, vitality, dedication and concentration. In terms of vitality factor, the averages difference between freshman and senior is significant, and freshman is lower than senior, which shows that the freshman students of physical education major are less active, persistent and willing to participate in learning than senior students.

Different majors of physical education were taken as independent variables, learning engagement and scores of each factor as dependent variables, factor analysis of variance was conducted. The results are shown as Table 9.

Table 9

Different Majors of Students Learning Engagement Comparison

\begin{tabular}{lcccc}
\hline Majors & Learning engagement & Vitality & Dedication & Concentration \\
\hline Physical education & $3.37 \pm 0.85$ & $3.22 \pm 0.92$ & $3.41 \pm 0.92$ & $3.41 \pm 0.96$ \\
Leisure sports & $3.36 \pm 0.86$ & $3.33 \pm 0.81$ & $3.36 \pm 0.83$ & $3.39 \pm 0.86$ \\
Management of social sports & $3.22 \pm 0.62$ & $3.06 \pm 0.62$ & $3.25 \pm 0.72$ & $3.22 \pm 0.65$ \\
Human exercise science & $3.43 \pm 0.72$ & $3.27 \pm 0.79$ & $3.47 \pm 0.77$ & $3.52 \pm 0.89$ \\
Sports teaching & $3.41 \pm 0.86$ & $3.15 \pm 0.95$ & $3.46 \pm 1.01$ & $2.56 \pm 0.88$ \\
Physical education training & $3.62 \pm 0.62$ & $3.45 \pm 0.76$ & $3.66 \pm 0.68$ & $3.82 \pm 0.68$ \\
Exercise training & $3.55 \pm 0.62$ & $3.32 \pm 0.66$ & $3.49 \pm 0.72$ & $3.78 \pm 0.81$ \\
Sports social humanities & $3.66 \pm 0.56$ & $3.43 \pm 0.72$ & $3.71 \pm 0.72$ & $3.78 \pm 0.66$ \\
Social sports & $3.65 \pm 0.63$ & $3.58 \pm 0.75$ & $3.71 \pm 0.60$ & $3.58 \pm 0.82$ \\
Others & $3.32 \pm 0.72$ & $3.11 \pm 0.76$ & $3.35 \pm 0.86$ & $3.45 \pm 0.83$ \\
F & 1.119 & 1.073 & 1.568 & 1.288 \\
P & 0.337 & 0.382 & 0.122 & 0.234 \\
\hline
\end{tabular}

Note. $* \mathrm{P}<0.05, * * \mathrm{P}<0.01$

From Table 9 we can see that there is no significant difference in learning engagement and scores of different factors among different majors. The average value of dedication, concentration and learning engagement of different majors is higher than that of vitality.

Social support refers to the spiritual and material comfort, care, respect and assistance to individuals from family, relatives and friends and other aspects of society. Research on work and learning engagement shows that social support has a significant predictive effect on individual engagement. Self-factor is an important internal factor affecting learning, but in the study of learning engagement, social support and self-factor have not been paid enough attention to.

Correlation analysis between student learning engagement and social support and self-factors are shown in Table 10.

Table 10

Correlation Analysis Between Student Learning Engagement and Social Support and Self-Factors

\begin{tabular}{lcc}
\hline & Self-factors & Social support \\
\hline Learning engagement & $-0.138^{* *}$ & $0.176^{* *}$ \\
Vitality & $-0.134^{* *}$ & $0.159^{* *}$ \\
Dedication & $-0.139^{* *}$ & $0.174^{* *}$ \\
Concentration & -0.092 & $0.129^{* *}$ \\
\hline
\end{tabular}

Note. $\mathrm{P}<0.05, * * \mathrm{P}<0.01$ 
Zhang / Evaluation model of college students' sports learning engagement factors based on big data analysis

From Table 10 we can see that there was a significant positive correlation between the learning engagement and social support of the students majoring in physical education, but a significant negative correlation with self-factors except concentration.

\section{Evaluation model construction of college students' sports learning engagement factors}

According to the big analysis results of the questionnaire data and the comparable indicators of NSSE survey, it is considered that the learning engagement model of college students majoring in physical education can include the level of active cooperative learning level, deep learning method, theoretical course learning engagement, professional training engagement and expansive learning engagement.

Active cooperative learning refers to the behavior of teachers, students and classmates to cooperate, communicate, discuss and share in the face of learning tasks. Based on the understanding of the meaning and thought behind the acquisition content, the deep learning method integrates the learning content structurally by means of association, critical thinking, content integration and knowledge application. Theoretical course learning engagement is the attitude and behavior level of students to theoretical knowledge and theoretical course learning. Professional training engagement is the attitude and behavior level of students to specific learning, training, competition and other activities. Expansive learning engagement is the degree of students' rich experience in learning or practical activities other than professional learning inside and outside the college. Thus, a five-dimension evaluation model of learning engagement for sports major student is constructed theoretically. The model is shown in Figure 2.

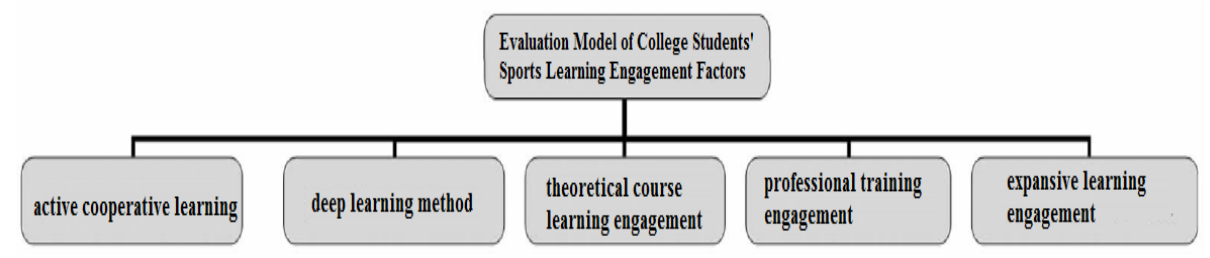

Figure 2. Evaluation Model of College Students' Sports Learning Engagement Factors

For formulating the dimensions of learning engagement evaluation, project analysis, factor analysis, reliability and validity analysis and other methods were mainly used based on the questionnaire.

The validity of the model is verified by statistical analysis of the characteristic roots, variance contribution rate and cumulative variance contribution rate of each factor in the questionnaire data. The characteristic roots, variance contribution rate and cumulative variance contribution rate of each factor is shown in Table 11.

Correlation coefficient between dimensions is shown in Table 12.

From Table 12, we can see that there is a significant positive correlation between each dimension, it means that they have a high content validity, the model is valid and correct. 
Table 11

The Characteristic Roots, Variance Contribution Rate and Cumulative Variance Contribution Rate of Each Factor

\begin{tabular}{cccccccccc}
\hline \multirow{2}{*}{ Dimension } & \multicolumn{3}{c}{ Initial } & \multicolumn{3}{c}{ Extracting squares sum } & \multicolumn{3}{c}{ Rotation squares sum } \\
\cline { 2 - 10 } & total & variance & Acc. & total & variance & Acc. & total & variance & Acc. \\
\hline 1 & 9.61 & 38.45 & 38.45 & 9.61 & 38.45 & 38.45 & 3.82 & 15.41 & 15.41 \\
2 & 2.34 & 9.47 & 47.82 & 2.34 & 47.82 & 47.82 & 3.57 & 14.31 & 29.65 \\
3 & 1.52 & 6.16 & 52.78 & 1.52 & 6.16 & 52.78 & 2.96 & 11.98 & 40.69 \\
4 & 1.27 & 5.06 & 58.22 & 1.27 & 5.06 & 58.22 & 2.86 & 11.56 & 53.97 \\
5 & 1.07 & 4.18 & 63.26 & 1.07 & 4.18 & 63.26 & 2.55 & 10.18 & 63.26 \\
\hline
\end{tabular}

Table 12

Correlation Coefficient Between Dimensions

\begin{tabular}{|c|c|c|c|c|c|c|}
\hline Dimension & $\begin{array}{c}\text { active } \\
\text { cooperative } \\
\text { learning }\end{array}$ & $\begin{array}{c}\text { deep } \\
\text { learning } \\
\text { method }\end{array}$ & $\begin{array}{l}\text { theoretical } \\
\text { course } \\
\text { learning } \\
\text { engagement }\end{array}$ & $\begin{array}{l}\text { professional } \\
\text { training } \\
\text { engagement }\end{array}$ & $\begin{array}{c}\text { expansive } \\
\text { learning } \\
\text { engagement }\end{array}$ & $\begin{array}{c}\text { Learning } \\
\text { engagement }\end{array}$ \\
\hline $\begin{array}{l}\text { active } \\
\text { cooperative } \\
\text { learning }\end{array}$ & 1 & & & & & \\
\hline $\begin{array}{l}\text { deep } \\
\text { learning } \\
\text { method } \\
\end{array}$ & $0.398 * *$ & 1 & & & & \\
\hline $\begin{array}{l}\text { theoretical } \\
\text { course } \\
\text { learning } \\
\text { engagement }\end{array}$ & $0.476^{* *}$ & $0.286^{* *}$ & 1 & & & \\
\hline $\begin{array}{l}\text { professional } \\
\text { training } \\
\text { engagement }\end{array}$ & $0.628 * *$ & $0.459 * *$ & $0.596 * *$ & 1 & & \\
\hline $\begin{array}{l}\text { expansive } \\
\text { learning } \\
\text { engagement }\end{array}$ & $0.475^{* *}$ & $0.601 * *$ & $0.407 * *$ & $0.631 * *$ & 1 & \\
\hline $\begin{array}{l}\text { Learning } \\
\text { engagement }\end{array}$ & $0.798 * *$ & $0.712 * *$ & $0.675 * *$ & $0.960 * *$ & $0.831 * *$ & 1 \\
\hline
\end{tabular}

\section{Conclusion}

Our study found that the overall situation of physical education students' learning engagement is not good, and the teachers should pay attention to it. There are significant differences in gender, grade and other aspects of learning engagement among students in physical education, but there are no significant differences in different majors. Engagement of female is obviously higher than male, and the higher students' learning engagement is also increased. Self-factors and social support can be used as predictive variables of sports majors' learning engagement, and social support has a positive predictive effect. 


\section{References}

Beyraamee, M., Haashemee, T., Abdollaahee, A. A. V., \& Alaaee, P. (2011). The relationship between goal orientation, self-efficacy, learning strategies, and academic achievement among high school sophomores in tabreez. Leonardo, 7(2), 173. http:// dx.doi.org/10.2307/1572807

Gregg, N. (2012). Increasing access to learning for the adult basic education learner with learning disabilities: evidence-based accommodation research. Journal of Learning Disabilities, 45(1), 47-63. http:// dx.doi.org/10.1177/0022219411426855

Hong-Wei, H. U., Zhou, X. J., Yang, X. Y., \& Ran, G. (2009). Analysis of clutch engagement judder and its influence factors. Journal of Zhejiang University, 43(3), 535-539. http:// dx.doi.org/10.3785/j.issn.1008973X.2009.03.026

King, M., \& Witney, L. W. (1998). Evaluation of engaged learning activities used in an interactive television course., 1998(1), 11.

Kuh, G. D. (2001). Assessing what really matters to student learning: inside the national survey of student engagement. Change, 33(3), 10-66. http:// dx.doi.org/10.1080/00091380109601795

Liao, Y. G. (2011). College students 'academic self-efficacy effects on their learning value and engagement. Journal of Ningbo University.

Mazer, J. P. (2013). Validity of the student interest and engagement scales: associations with student learning outcomes. Communication Studies, 64(2), 125-140. http:// dx.doi.org/10.1080/10510974.2012.727943

Newmann, F. M. E. (1992). Student engagement and achievement in American secondary schools.

Pitsi, A., Digelidis, N., \& Papaioannou, A. (2015). The effects of reciprocal and self-check teaching styles in students' intrinsic-extrinsic motivation, enjoyment and autonomy in teaching traditional Greek dances. Journal of Physical Education \& Sport, 15, 352-361. http:// dx.doi.org/10.7752/jpes.2015.02053

Schaufeli, W. B., Salanova, M., González-romá, V., \& Bakker, A. (2002). The measurement of engagement and burnout: a two sample confirmatory factor analytic approach. Journal of Happiness Studies, 3(1), 71 92. http:// dx.doi.org/10.1023/a:1015630930326

Sibold, J. (2016). Learning "a la carte": a theory-based tool for maximizing student engagement. Journal of College Teaching \& Learning, 13(2), 79. http:// dx.doi.org/10.19030/tlc.v13i2.9641

Tian, H. W., \& Zhang, H. L. (2012). Survey of university student engagement: theoretical foundation and research progress. Journal of Yangzhou University, 16(6), 11-15.

Tian, L., Deng, R., (2016). Investigation on status quo and demand for on-site disaster relief medical training of non-medical college students in Gansu province. Chinese Journal of Disaster Medicine.

Weidenfeld, M. C., \& Fernandez, K. E. (2016). Does increase student engagement? an empirical evaluation of the use of historical simulations in teaching political theory. Journal of Political Science Education, 13, 116. http:// dx.doi.org/10.1080/15512169.2016.1175948

Zhang, X. Y. (2008). BIAN Xiao-hua Department of Psychology, East China Normal University, Shanghai 200062, China; A Study on the Relationship of Learning Burnout and Health-related Hardiness of Undergraduates (J). Chinese Journal of Clinical Psychology, 5. 